\title{
A numerical study of rotor eccentricity and dynamic load in induction machines for motor current analysis based diagnostics
}

\author{
Haiyang $\mathrm{Li}^{1}$, Zhexiang $\mathrm{Zou}^{2}$, Xiuquan $\mathrm{Sun}^{3}$, Fengshou Gu${ }^{4}$, Andrew D. Ball ${ }^{5}$ \\ $1,2,3,4,5$ Centre for Efficiency and Performance Engineering, University of Huddersfield, \\ Huddersfield, HD1 3DH, United Kingdom \\ ${ }^{2}$ School of Industrial Automation, Beijing Institute of Technology Zhuhai, ZHBIT, Zhuhai, China \\ ${ }^{4}$ Corresponding author \\ E-mail: ${ }^{1}$ haiyang.li@hud.ac.uk, ${ }^{2}$ zhexiang.zou@hud.ac.uk, ${ }^{3} x i u q u a n . s u n @ h u d . a c . u k,{ }^{4}$.gu@hud.ca.uk, \\ 5a.ball@hud.ac.uk
}

Received 1 June 2021; accepted 2 July 2021

DOI https://doi.org/10.21595/mrcm.2021.22145

Check for updates

Copyright $(C 2021$ Haiyang Li, et al. This is an open access article distributed under the Creative Commons Attribution License, which permits unrestricted use, distribution, and reproduction in any medium, provided the original work is properly cited.

\begin{abstract}
The asymmetry in the manufacturing and assembling is the common issue of rotor systems. Different degrees of errors are inevitable in alternating current (AC) motors, which causes degraded performances. Furthermore, around $80 \%$ of mechanical faults link to rotor eccentricity. The eccentricity faults (EFs) generate excessive mechanical stress and then lead to fatigue in the other parts of the motor. Motor current signal analysis (MCSA) can be used to diagnose induction machine (IM) faults. As the EF leads to an unequal air gap when the rotor rotates, the inductance of IM also responds to the EF. Moreover, the dynamic load is a typical situation due to residual dynamic unbalance and misalignment. To study how EFs and dynamic load affect the stator current. The current model of symmetrical motor, asymmetrical motors with three-level EFs and with dynamic load are investigated numerically. The correctness of models is verified through experimental study. The results show the level of EF affects the sideband peak values significantly in the stator current spectrum. These findings will provide a foundation for the accurate diagnosis of motor health conditions.
\end{abstract}

Keywords: motor current signal analysis, modelling, eccentricity fault, dynamic load, induction machine.

\section{Introduction}

Eccentricity faults (EFs) refer to the air-gap space between stator and rotor that varies when the induction machine (IM) is working [1]. $80 \%$ of mechanical faults result in rotor eccentricity [2]. The eccentric motor generates excessive mechanical stress and then leads to fatigue in the bearing [3]. Although motor manufacturers make every effort to minimise the asymmetry in the manufacturing and assembling, the error still exists [4]. As Fig. 1 shows, eccentricity faults include static eccentricity (SE) fault, dynamic eccentricity (DE) fault and mixed eccentricity fault of SE and DE [5]. SE refers to the air-gap space is fixed when the rotor rotates. However, the air gap at different radians is unequal as Fig. 1(b) shows. As illustrated in Fig. 1(c), DE fault refers to the space change periodically at a fixed circumferential position periodically. Fig. 1(d) shows the mixed eccentricity of SE and DE.

Misalignment is the main cause for SE [1]. Misalignment causes the rotor's physical centre away from the stator centre. DE usually results from oval cores, bent shaft and worn bearings [6].

Motor current signal analysis (MCSA) is an effective method used to diagnose EF faults [7], [8], [9]. To study how EFs affect the stator current. The current model of symmetrical motor, asymmetrical motors with three-level EFs are investigated numerically.

Rotor eccentricity results in an unbalanced magnetic pull. Consequently, vibration, acoustic noise, increasing in stator-rotor rub, bearing wearing and/or rotor deflection failure will happen. It also, which might have bad effects on the stator or rotor core, conductor, and/or insulation [10]. 
The low-frequency range of dynamic eccentricity frequency is:

$f_{e f}=f_{r}$

The fault related sidebands around the supply frequency are:

$f_{\text {efsideband }}=f_{s} \pm k f_{r}$

where $f_{s}$ and $f_{r}$ represent supply frequency and rotating frequency, respectively. $k=1,2,3 \ldots$ represents the order of the sideband.

Dynamic load faults come from external faults instead of from an IM. It is mainly caused by gearbox transmission failure, load imbalance and misalignment [11]. The load faults primarily cause a non-constant load torque with time [12].

If the load torque oscillates as the IM working, the current will be modulated with spectral components related to abnormal load faults [13]. The supply current signal in the healthy motor is sinusoidal. Any torque oscillation at a multiple of the rotational speed will produce stator currents at eccentricity frequency (Eq. (1) (2)) [14].

The rest of this article consists of four sections. Section 2 proposes a motor current model of symmetrical motor and asymmetrical motor with different level EFs. Section 3 carries out simulation analysis using MATLAB software. Section 4 set up the experiment and presents the test procedure to verify the proposed model. Section 5 analyses the test data and discuss the results. Section 6 concludes this work.

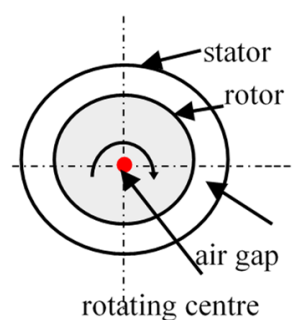

a) Healthy case

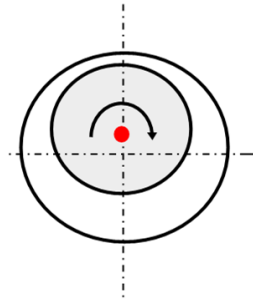

b) Static eccentricity

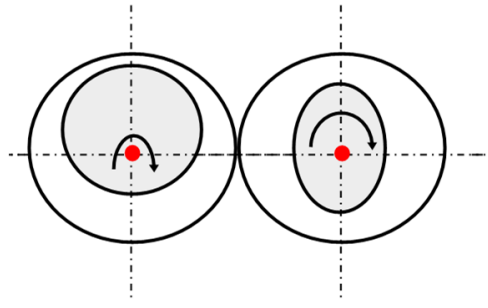

c) Dynamic eccentricity

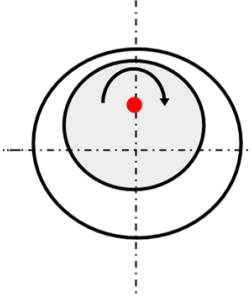

d) Mix eccentricity

Fig. 1. Different types of air-gap eccentricity faults

\section{Motor current models}

\subsection{Motor current model of healthy motor}

A three-phase IM has three-phase distributed windings, displaced relative to each other by 120 degrees, each of the stator and rotor winding circuits has the same form of the voltage equations. According to Kirchhoffs Voltage Law the voltage equation can be given as [15]:

$V=I R+\frac{d \varphi}{d t}=I R+\frac{d}{d t}(L I)=I R+I \frac{d L}{d t}+L \frac{d I}{d t}$

where $V$ and $I$ are the voltage and current vector matrices, respectively, $R$ represents the motor resistance and $L$ is the inductance matrix. An equivalent circuit of the symmetrical rotor is shown in Fig. 2. If $V$ is the voltage vector, then:

$V=\left[\begin{array}{ll}V_{S} & V_{R}\end{array}\right]=\left[\begin{array}{lllllllll}V_{A S} & V_{B S} & V_{C S} & V_{r 1} & V_{r 2} & V_{r 3} & \ldots & V_{r n} & V_{e}\end{array}\right]^{T}$,

where $V_{S}$ and $V_{R}$ represent stator voltage vector and rotor voltage vector, respectively. $V_{A S}, V_{B S}$, $V_{C S}$ are the voltage of phases $\mathrm{A}, \mathrm{B}$, and $\mathrm{C}$. There are $n$ bars in the rotor. $V_{r i}(i=1,2,3 \ldots n)$ 
represent the voltage of the $i$ th rotor bar. $V_{e}$ is the voltage in the end ring. If $I$ is the current vector, then:

$$
I=\left[\begin{array}{ll}
I_{S} & I_{R}
\end{array}\right]=\left[\begin{array}{lllllllll}
I_{A S} & I_{B S} & I_{C S} & I_{r 1} & I_{r 2} & I_{r 3} & \ldots & I_{r n} & I_{e}
\end{array}\right]^{T},
$$

where $I_{S}$ and $I_{R}$ represent stator current vector and rotor current vector, respectively. $I_{A S}, I_{B S}, I_{C S}$ are currents of phases A, B, and C. $I_{r i}(i=1,2,3, \ldots, n)$ represents the current of the $i$ th rotor bar. $I_{e}$ is the current in the end ring.

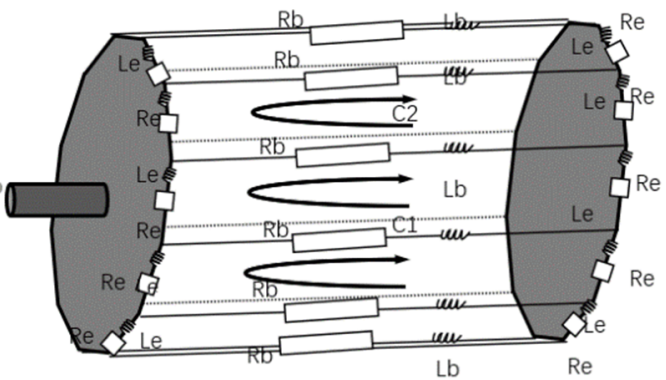

Fig. 2. Equivalent circuit of the asymmetrical rotor

The inductance $L$ is expressed as:

$L=\left[\begin{array}{ll}L_{S S} & L_{S R} \\ L_{R S} & L_{R R}\end{array}\right]$

where $L_{S S}$ is the stator self-inductance, $L_{S R}$ is the stator-to-rotor inductance, $L_{R S}$ is the rotor-to stator inductance, and $L_{R R}$ is the rotor self-inductance. see Eqs. (7) to (20):

$L_{S S}=\left[\begin{array}{lll}L_{A S A S} & L_{A S B S} & L_{A S C S} \\ L_{B S A S} & L_{B S B S} & L_{B S C S} \\ L_{C S A S} & L_{C S B S} & L_{C S C S}\end{array}\right]$.

The inductances are given as follows:

$L_{X Y}\left(\theta_{r}\right)=\mu_{0} r l \int_{0}^{2 \pi} \frac{N_{X}(\varphi) N_{Y}(\varphi)}{g\left(\varphi, \theta_{r}\right)} d \varphi$,

where: $\mu_{0}$ - permeability of free space, $r$ - effective radius of the air gap, $l$ - machine stack length, $N_{X}(\varphi), N_{Y}(\varphi)$ - the winding functions for windings $X$ and $Y$ respectively which depends solely on the spatial stator circumferential position $\varphi, g\left(\varphi, \theta_{r}\right)$ - air gap function, $\theta_{r}-$ rotor circumferential position.

\subsubsection{Stator self-inductance calculation}

According to the matrix equations, the stator-to-stator inductance can be derived as [16]:

$$
\begin{gathered}
L_{A S A S}=\mu_{0} r l \int_{0}^{2 \pi} \frac{N_{A S}(\varphi) \times N_{A S}(\varphi)}{g\left(\varphi, \theta_{r}\right)} d \varphi=\mu_{0} r l \int_{0}^{2 \pi} \frac{N_{S} \cos (p \varphi) \times N_{S} \cos (p \varphi)}{g_{0}} d \varphi \\
=\frac{\mu_{0} r l \pi N_{S}^{2}}{g_{0}},
\end{gathered}
$$

where: 


$$
\begin{aligned}
& N_{A S}=N_{S} \cos (p \varphi), \quad N_{B S}=N_{S} \cos \left(p \varphi-\frac{2 \pi}{3}\right), \quad N_{C S}=N_{S} \cos \left(p \varphi+\frac{2 \pi}{3}\right), \\
& N_{R 1}=n \cos \left(p\left(\varphi-\theta_{r}\right)\right), \quad N_{R 2}=n \cos \left(p\left(\varphi-\theta_{r}\right)+\frac{2 \pi}{n}\right), \ldots \ldots, \\
& N_{R n}=n \cos \left(p\left(\varphi-\theta_{r}\right)+\frac{2 \pi(n-1)}{n}\right),
\end{aligned}
$$

where $g_{0}$ is constant and represent the airgap for the healthy motor. $p$ represents pole pairs of induction machines.

$N_{S}$ is the number of the stator turns similarly:

$$
\begin{aligned}
& L_{A S A S}=L_{B S B S}=L_{C S C S}=\frac{\mu_{0} r l \pi N_{S}{ }^{2}}{g_{0}}, \\
& L_{A S B S}=L_{B S A S}=L_{B S C S}=L_{C S B S}=L_{A S C S}=L_{C S A S}=-\frac{\mu_{0} r l \pi N_{S}{ }^{2}}{2 g_{0}}, \\
& L_{S S}=\left[\begin{array}{lll}
L_{A S A S} & L_{A S B S} & L_{A S C S} \\
L_{B S A S} & L_{B S B S} & L_{B S C S} \\
L_{C S A S} & L_{C S B S} & L_{C S C S}
\end{array}\right]=L_{m S}\left[\begin{array}{ccc}
1 & -0.5 & -0.5 \\
-0.5 & 1 & -0.5 \\
-0.5 & -0.5 & 1
\end{array}\right],
\end{aligned}
$$

where $L_{m s}=\frac{\mu_{0} r l \pi N_{S}{ }^{2}}{g_{0}}$.

\subsubsection{Stator-to-rotor inductance calculation}

$$
\begin{aligned}
& L_{S R}=L_{R S}^{\prime}=\left[\begin{array}{lllll}
L_{S A R 1} & L_{S A R 2} & \cdots & L_{S A R n} & L_{S A R e} \\
L_{S B R 1} & L_{S B R 2} & \cdots & L_{S B R n} & L_{S B R e} \\
L_{S C R 1} & L_{S C R 2} & \cdots & L_{S C R n} & L_{S C R e}
\end{array}\right], \\
& L_{S A R 1}\left(\theta_{r}\right)=\mu_{0} r \int_{0}^{2 \pi} \frac{N_{S A}(\varphi) N_{R 1}(\varphi)}{g\left(\varphi, \theta_{r}\right)} d \varphi=\frac{\mu_{0} r l \pi N_{S} n}{2 g_{0}} \cos \left(\theta_{r}\right) .
\end{aligned}
$$

Similarly:

$$
\begin{aligned}
& L_{S A R 2}\left(\theta_{r}\right)=\mu_{0} r l \int_{0}^{2 \pi} \frac{N_{S A}(\varphi) N_{R 2}(\varphi)}{g\left(\varphi, \theta_{r}\right)} d \varphi=\frac{\mu_{0} r l \pi N_{S} n}{2 g_{0}} \cos \left(\theta_{r}+\frac{2 \pi}{n}\right), \\
& L_{S A R n}\left(\theta_{r}\right)=\mu_{0} r l \int_{0}^{2 \pi} \frac{N_{S A}(\varphi) N_{R n}(\varphi)}{g\left(\varphi, \theta_{r}\right)} d \varphi=\frac{\mu_{0} r l \pi N_{S} n}{2 g_{0}} \cos \left(\theta_{r}+\frac{2 \pi(n-1)}{n}\right), \\
& L_{S B R n}\left(\theta_{r}\right)=\mu_{0} r l \int_{0}^{2 \pi} \frac{N_{S B}(\varphi) N_{R n}(\varphi)}{g\left(\varphi, \theta_{r}\right)} d \varphi=\frac{\mu_{0} r l \pi N_{S} n}{2 g_{0}} \cos \left(\theta_{r}-\frac{2 \pi}{3}+\frac{2 \pi(n-1)}{n}\right), \\
& L_{S C R n}\left(\theta_{r}\right)=\mu_{0} r l \int_{0}^{2 \pi} \frac{N_{S C}(\varphi) N_{R n}(\varphi)}{g\left(\varphi, \theta_{r}\right)} d \varphi=\frac{\mu_{0} r l \pi N_{S} n}{2 g_{0}} \cos \left(\theta_{r}+\frac{2 \pi}{3}+\frac{2 \pi(n-1)}{n}\right) .
\end{aligned}
$$

\subsubsection{Rotor self-inductance calculation}

$L_{R R}=\left[\begin{array}{ccccc}L_{R 1 R 1} & L_{R 1 R 2} & \cdots & L_{R 1 R n} & L_{R 1 R e} \\ L_{R 2 R 1} & L_{R 2 R 2} & \cdots & L_{R 2 R n} & L_{R 2 R e} \\ L_{R 3 R 1} & L_{R 3 R 2} & \cdots & L_{R 3 R n} & L_{R 3 R e} \\ \cdots & \cdots & \cdots & \cdots & \cdots \\ L_{R n R 1} & L_{R n R 2} & \cdots & L_{R n R n} & L_{R n R e}\end{array}\right]$,

where the $L_{\text {RiRy }}(i, y=1,2,3, \ldots, n)$ can be calculated using Eq. (20): 
$L_{R i R y}=\mu_{0} r l \int_{0}^{2 \pi} \frac{N_{R i}(\varphi) N_{R y}(\varphi)}{g\left(\varphi, \theta_{r}\right)} d \varphi=\frac{\mu_{0} r l \pi n^{2}}{2 g_{0}} \cos \left(\frac{2 \pi(y-i)}{n}\right)$.

$R$ is the resistance matrix [8] and is given in Eq. (21). The matrices of stator resistance $R_{S S}$ and rotor resistance $R_{R R}$ are given in Eqs. (22) and (24), respectively:

$R=\left[\begin{array}{ll}R_{S S} & R_{S R} \\ R_{R S} & R_{R R}\end{array}\right]$

$R_{S S}=\left[\begin{array}{ccc}R_{A S} & 0 & 0 \\ 0 & R_{B S} & 0 \\ 0 & 0 & R_{C S}\end{array}\right]$,

$R_{R S}=R_{S R}^{\prime}=\left[\begin{array}{ccccc}0 & 0 & 0 & \cdots & 0 \\ 0 & 0 & 0 & \cdots & 0 \\ 0 & 0 & 0 & \cdots & 0\end{array}\right]$

$R_{R R}=\left[\begin{array}{cccccc}2\left(R_{b}+R_{e}\right) & -R_{b} & 0 & \ldots & -R_{b} & -R_{e} \\ -R_{b} & 2\left(R_{b}+R_{e}\right) & -R_{b} & \ldots & 0 & -R_{e} \\ 0 & -R_{b} & 2\left(R_{b}+R_{e}\right) & \ldots & 0 & -R_{e} \\ 0 & 0 & -R_{b} & \ldots & 0 & -R_{e} \\ \cdots & \ldots & \ldots & \cdots & \cdots & \cdots \\ -R_{b} & 0 & 0 & \ldots & 2\left(R_{b}+R_{e}\right) & -R_{e} \\ -R_{e} & -R_{e} & -R_{e} & -R_{e} & -R_{e} & n R_{e}\end{array}\right]$.

According to Eq. (3), the current differential equation of the healthy motor is derived as follows:

$\frac{d I}{d t}=\left[V-I\left(R+\omega \frac{d}{d \theta_{r}}\left(L\left(\theta_{r}\right)\right)\right)\right] L\left(\theta_{r}\right)^{-1}$.

To obtain the speed and displacement of the rotor which are required to calculate the cross inductances in Eqs. (13)-(18), dynamic load balance equation is given as follows:

$J \frac{d \omega}{d t}=J \frac{d^{2} \theta_{r}}{d t^{2}}=T_{e}-T_{l}$

where $J$ represents mechanical inertial. $T_{l}$ represent external load. The electric torque $T_{e}$ is given in Eq. (27) [15]:

$T_{e}=\frac{1}{2}[I]^{T} \frac{\partial L\left(\theta_{r}\right)}{\partial \theta_{r}}[I]$

\subsection{Motor current model of eccentricity motor}

According to the current differential equation of the healthy motor in Eq. (25), the current will respond to the changes in the voltage $V$, inductance $L$, resistance $R$ and rotor angular speed $\omega$. For the asymmetrical motor, the voltage $V$, resistance $R$ and angular speed $\omega$ are the same as for a healthy motor.

According to Eq. (8), The inductance is affected by the air-gap $g\left(\varphi, \theta_{r}\right)$. For a healthy motor, the air gap $\left(g_{0}\right)$ is constant, see Fig. 3(a). With an eccentricity fault, the air-gap at a given point on the stator between the stator and rotor will change $\left(g_{x}\right)$ as the rotor rotates, see Fig. 3(b). Therefore, the inductance matrix for a motor with an eccentricity fault $\left(L_{e f}\right)$ will be different from that of a healthy motor $(L)$.

The air-gap distance for an eccentric rotor is: 
$g_{x}=g_{0}\left[1-\rho \cos \left(\theta_{r}\right)\right]$

where $\rho$ is degree of eccentricity.

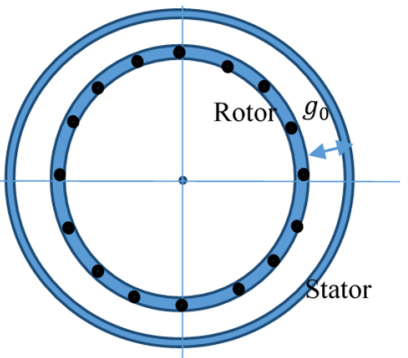

a) Healthy motor

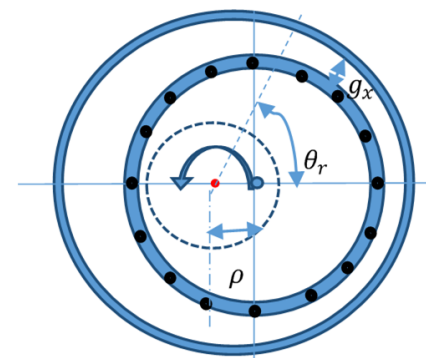

b) Motor with eccentricity fault

Fig. 3. Eccentricity fault: schematic diagram

For $g_{0}=1$, and $\rho=0.001$ as an example, the air gap $g_{x}$ changes with the rotation angle, as shown in Fig. 4.

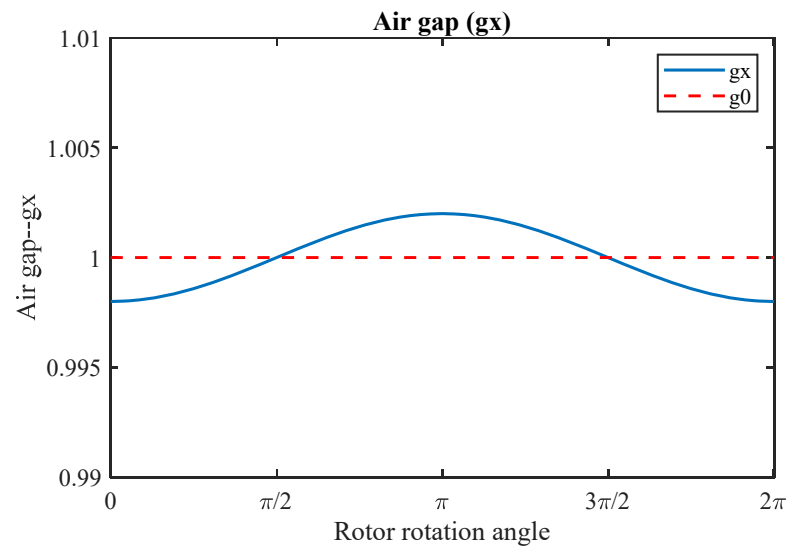

Fig. 4. Schematic diagram of change in the air gap, where $g_{x}=1\left(1-0.001 \cos \left(\theta_{r}\right)\right)$

The inductance of the eccentric motor is given in Eq. (29):

$L_{e f}=\left[\begin{array}{ll}L_{e f S S} & L_{e f S R} \\ L_{e f R S} & L_{e f R R}\end{array}\right]$.

The air gap changes as the rotor rotates, the stator self-inductance $\left(L_{e f S S}\right)$, rotor self-inductance $\left(L_{e f R R}\right)$ and mutual inductance of an eccentric motor $\left(L_{e f S R}\right)$ are given as follows:

$L_{e f S S}=\frac{L_{S S}}{g_{x}}=\frac{L_{S S}}{g_{0}\left(1-\rho \cos \left(\theta_{r}\right)\right)^{\prime}}$

$L_{e f R R}=\frac{L_{R R}}{g_{x}}=\frac{L_{R R}}{g_{0}\left(1-\rho \cos \left(\theta_{r}\right)\right)^{\prime}}$,

$L_{e f S R}=L_{e f R S}^{\prime}=\frac{L_{S R}}{g_{x}}=\frac{L_{S R}}{g_{0}\left(1-\rho \cos \left(\theta_{r}\right)\right)}$

Therefore, the current differential equation for the motor with an eccentricity fault can be written as: 
$\frac{d I_{e f}}{d t}=\left[V-I\left(R+\omega \frac{d}{d \theta_{r}}\left(L_{e f}\left(\theta_{r}\right)\right)\right)\right] L_{e f}\left(\theta_{r}\right)^{-1}$.

\subsection{Motor current model of dynamic load}

When there are time-varying external loads such as rotor DE and unbalances, the airgap, inductance, and resistance are the same as the healthy condition. The variable parameters would be the external load $T_{l}$ which can be modelled by Eq. (34):

$T_{l}=T_{b}\left[1-\delta_{l} \sin \left(\theta_{r}-\theta_{l}\right)\right]$

where $T_{b}$ is constant load. $\delta_{l}$ is the coefficient of the dynamic load, $\theta_{l}$ represent the original angle. The external load $T_{l}$ can be set as a constant or time-varying one to correspond to different load scenarios according to set the coefficient $\delta_{l}$.

Combining the resistance and inductance matrices with the current differential equation, etc., the current of the healthy motor, the motor with different degree eccentricity and motor with dynamic working load can be calculated and simulated as described in Section 3.

\section{Eccentricity motor simulation analysis}

\subsection{Motor current characteristics with eccentricity}

The parameters of the simulation at set up are as shown in Table 1.

Table 1. Parameters used in simulations

\begin{tabular}{|c|c|c|}
\hline Category & Main parameters & Technical data \\
\hline \multirow{10}{*}{ Motor } & Supply power & $3.0 \mathrm{~kW}$ \\
\hline & Supply voltage $(V)$ & $220 \mathrm{~V}$ \\
\hline & Supply frequency $\left(f_{s}\right)$ & $50 \mathrm{~Hz}$ \\
\hline & $\begin{array}{c}\text { Torque }\left(T_{b}\right) \\
\text { Mechanical inertia }(J)\end{array}$ & $\begin{array}{c}15.7 \mathrm{~N} \cdot \mathrm{m} \\
0.089\end{array}$ \\
\hline & Angular speed $(\omega)$ & $152.89 \mathrm{rad} / \mathrm{s}$ \\
\hline & Rated speed & $1460 \mathrm{rpm}$ \\
\hline & Number of bars $(n)$ & 28 \\
\hline & Number of turns per stator phase & 183 \\
\hline & Pole pairs $(p)$ & 2 \\
\hline & Phase & 3 \\
\hline \multirow{3}{*}{ Resistance } & Stator resistance $\left(R_{A S}=R_{B S}=R_{C S}\right)$ & $4.4 \Omega$ \\
\hline & Rotor bar resistance $\left(R_{b}\right)$ & $3.8 \times 10^{-5} \Omega$ \\
\hline & End ring resistance $\left(R_{e}\right)$ & $4.75 \times 10^{-5} \Omega$ \\
\hline \multirow{3}{*}{ Inductance } & Permeability of free space $\left(\mu_{0}\right)$ & $1.26 \times 10^{-6} \mathrm{H} / \mathrm{m}$ \\
\hline & Effective radius of the air gap $(r)$ & $0.0455 \mathrm{~m}$ \\
\hline & Machine stack length $(l)$ & $0.125 \mathrm{~m}$ \\
\hline \multirow{2}{*}{ Others } & Sampling frequency & $2000 \mathrm{~Hz}$ \\
\hline & Sampling time & $3 \mathrm{~s}$ \\
\hline
\end{tabular}

Based on the theoretical study in Section 2 and the parameter setting above, a simulation was carried out by solving the differential equations Eq. (24) and (32) using solver ode45 in MATLAB (Version: 2020a) software. The stator current of the healthy motor is shown in Fig. 5. The stator current is a sine wave, see Fig. 5(a). The current spectrum in Fig. 5(b) shows a substantial peak at the supply frequency is $50 \mathrm{~Hz}$, this will be the case in all the following simulations of the rotor and stator current spectrums.

For eccentricity studies, the simulation was implemented using the same parameters defined 
for the healthy model, but Eq. (29) (30) (31) are set with different degrees of eccentricity degree $(\rho)$ as shown in Table 2.
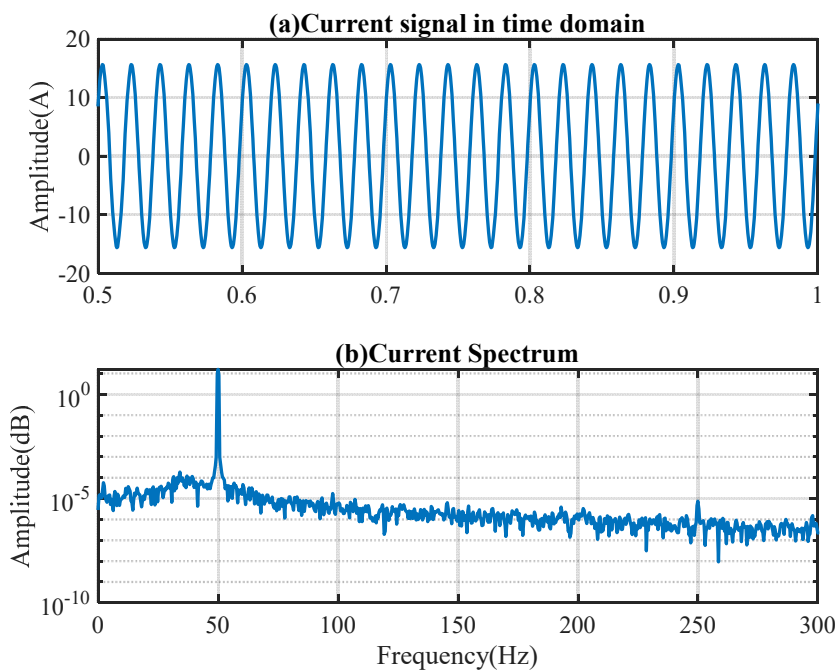

Fig. 5. Stator current signal for the healthy motor

Table 2. Parameters used for simulating different degrees of eccentricity

\begin{tabular}{|c|c|c|c|c|}
\hline Motor health condition & $\begin{array}{c}\text { Degree of } \\
\text { eccentricity }(\rho)\end{array}$ & Value & Notation in Figures & Others \\
\hline Healthy motor & $\rho 1$ & $0 \%$ & BL & Comparison case \\
\hline \multirow{3}{*}{ Motor with eccentricity fault } & $\rho 2$ & $0.2 \%$ & $0.2 \% \mathrm{EF}$ & \multirow{3}{*}{ Study cases } \\
\cline { 2 - 4 } & $\rho 3$ & $0.4 \%$ & $0.4 \% \mathrm{EF}$ & \\
\cline { 2 - 4 } & $\rho 4$ & $0.6 \%$ & $0.6 \% \mathrm{EF}$ & \\
\hline
\end{tabular}

According to the analysis made in Section 1, the eccentricity frequency occurs at frequencies of $f_{s} \pm k f_{r}$. The supply frequency, $f_{s}$ is $50 \mathrm{~Hz}$. the rotational frequency, $f_{r}$ is calculated from the rotational speed. $f_{r} \approx 24.1 \mathrm{~Hz}$, and the eccentricity fault $f_{\text {ef }}=50 \pm 24.1 \approx 25.9$ and $74.1 \mathrm{~Hz}$. The simulated stator current spectrum in Fig. 7 shows sidebands around the $50 \mathrm{~Hz}$ peak at fault frequencies of $25.9 \mathrm{~Hz}$ and $74.1 \mathrm{~Hz}$ for study cases but no sidebands for the healthy cases (BL). Furthermore, when an eccentricity was introduced, the speed fluctuated, see Fig. 6. The speed fluctuation increased with the degree of the eccentricity as did the amplitude of the sidebands.

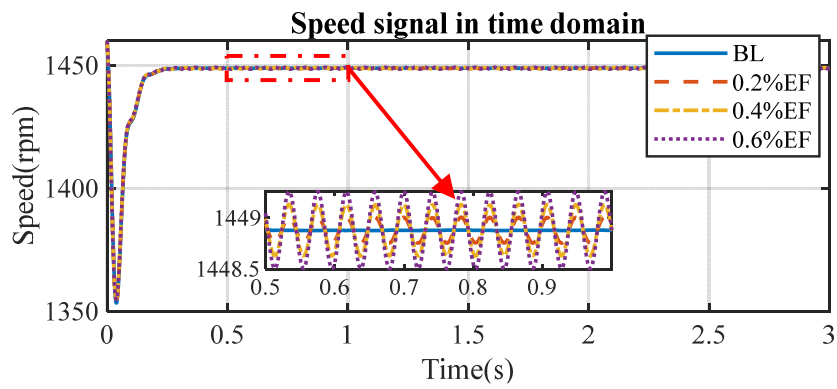

Fig. 6. The simulated speed with eccentricity faults

\subsection{Influences of dynamic load on motor current characteristics with eccentricity}

To simulate dynamic loads, the torque balance equation of Eq. (27) is set up as constant and dynamic as follows. 


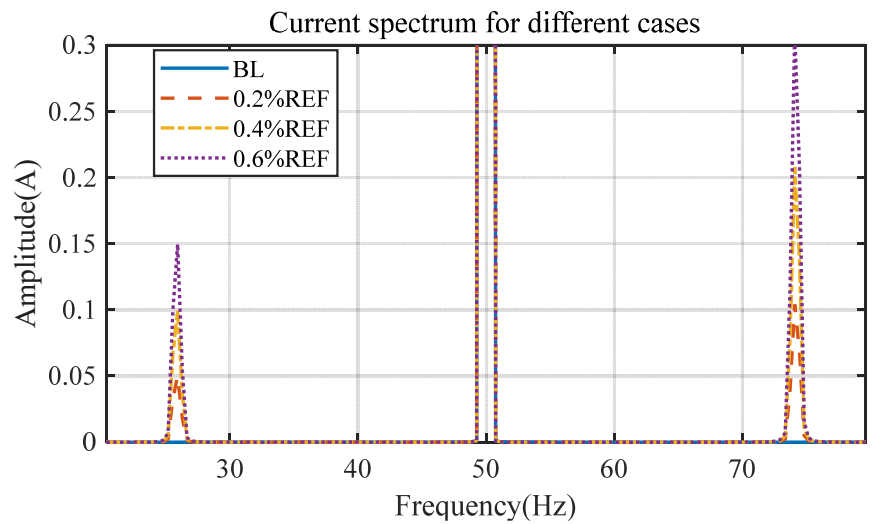

Fig. 7. Simulated stator current spectrum with eccentricity faults

Table 3. Parameters used for simulating dynamic load

\begin{tabular}{|c|c|c|c|c|}
\hline Cases & $\begin{array}{c}\text { Coefficient of the dynamic } \\
\text { load }\left(\delta_{l}\right)\end{array}$ & $\begin{array}{c}\text { Degree of } \\
\text { eccentricity }(\rho)\end{array}$ & $\begin{array}{c}\text { Notation in } \\
\text { Figures }\end{array}$ & $\begin{array}{c}\text { Original angel } \\
\theta_{l}\end{array}$ \\
\hline $\begin{array}{c}\text { Constant } \\
\text { load }\end{array}$ & \multirow{2}{*}{0} & $0 \%$ & $0 \%$ EF-cLd & \multirow{2}{*}{$0 ; \pi / 2 ;$} \\
\cline { 2 - 4 } $\begin{array}{c}\text { Dynamic } \\
\text { load }\end{array}$ & \multirow{2}{*}{0.02} & $0.2 \%$ & $0.2 \%$ EF-cLd & $\pi ; 3 \pi / 2$ \\
\cline { 2 - 4 } & $0.2 \%$ & $0.2 \%$ EF-dLd & \\
\hline
\end{tabular}

To better understand how the original angle affects the diagnosis results. All the cases with for original angles $\left(\theta_{l}=0 ; \pi / 2 ; \pi ; 3 \pi / 2\right)$ respectively.

Fig. 8 shows the speed of the healthy case $(0 \% \mathrm{EF}-\mathrm{cLd})$ is stable but with eccentricity or dynamic load fluctuation. When the motor with a $0.2 \%$ eccentricity, the speed under dynamic load fluctuates more than under constant load. Fig. 8 illustrate the speed of different cases with the original angles $\left(\theta_{l}\right)$ of $0, \pi / 2, \pi, 3 \pi / 2$. Fig. 8(a) and $8(\mathrm{~b})$ show when $\theta_{l}=0$ and $\pi / 2$, under the same dynamic load, the speed fluctuates more when eccentricity getting severe. However, the Fig. 8 (c) and (d) show when $\theta_{l}=\pi$ and $3 \pi / 2$, under the same dynamic load, the speed fluctuates less when eccentricity getting severe.

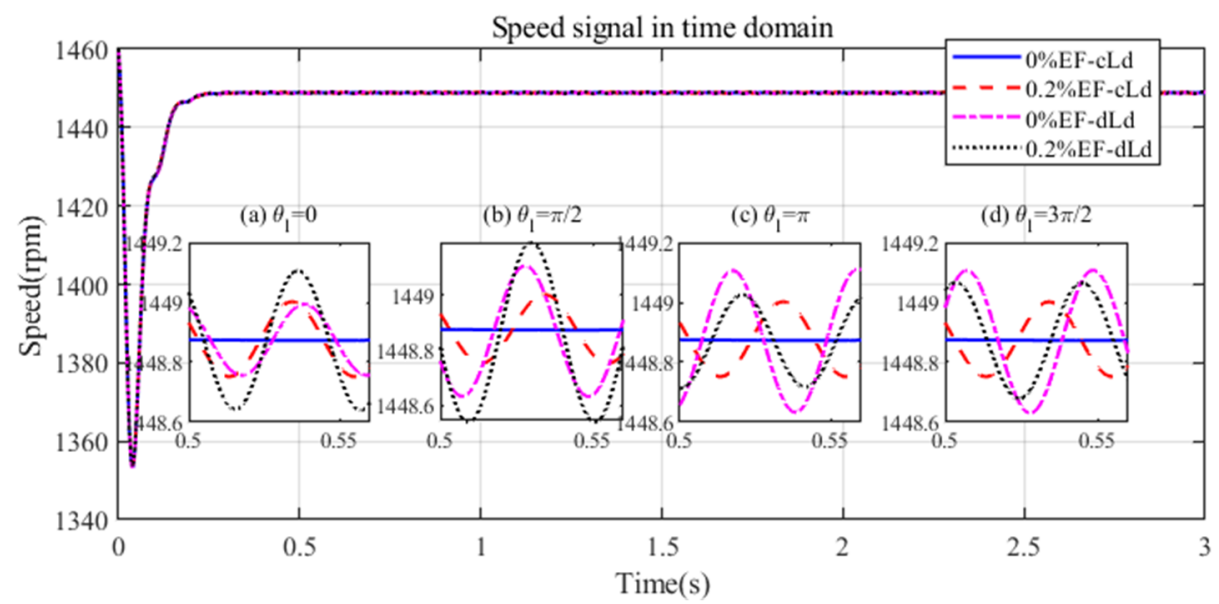

Fig. 8. The simulated speed with different degrees of eccentricity and dynamic load 


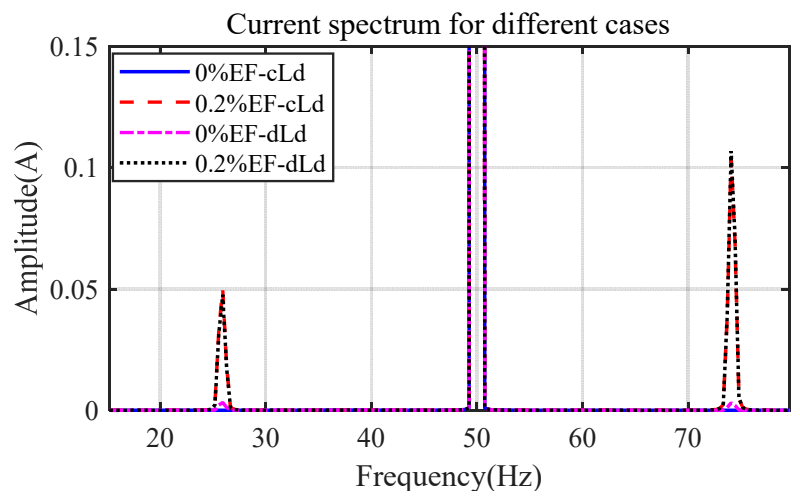

Fig. 9. Simulated current spectrum with eccentricity and dynamic load $\left(\theta_{l}=0\right)$

Fig. 9 shows the current spectrum of different dynamic load cases when $\theta_{l}=0$. there are sidebands for eccentricity or dynamic load cases. Take the lower sideband as the example, to better compare the sideband amplitude when $\theta_{l}$ changes, Fig. 10 illustrate the current spectrum of different cases with the original angels $\left(\theta_{l}\right)$ of $0, \pi / 2, \pi, 3 \pi / 2$. For a balance (no eccentricity) motor, the sidebands of cases under the dynamic load are higher than that under constant load. However, when the motor is with eccentricity, the sidebands of the dynamic load cases in the spectrum a related to the original angle.

(a) $\theta_{1}=0$

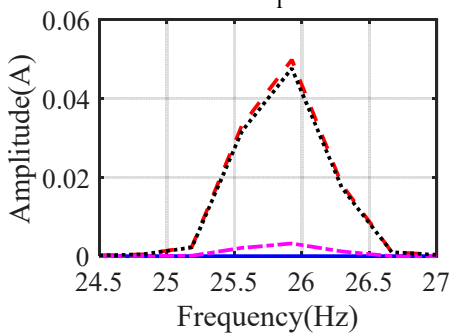

(c) $\theta_{1}=\pi$

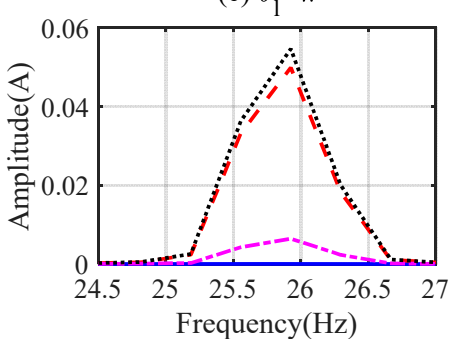

(b) $\theta_{1}=\pi / 2$

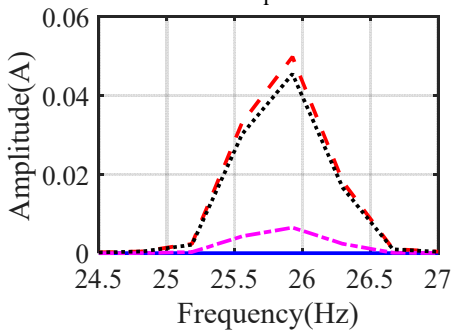

(d) $\theta_{1}=3 \pi / 2$

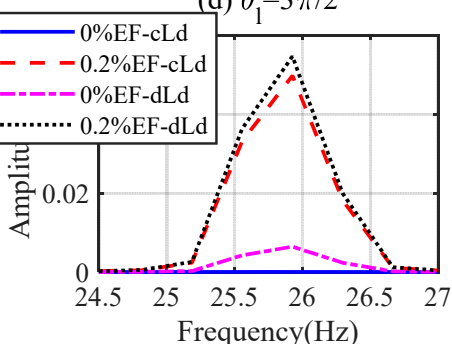

Fig. 10. Left sideband for different original angle a) $\theta_{l}=0$, b) $\theta_{l}=\frac{\pi}{2}$, c) $\theta_{l}=\pi$, and d) $\theta_{l}=\frac{\pi}{2}$

\section{Experimental setup and test procedure}

An IM test rig (Fig. 11) is set up to validate the proposed simulation. It includes an induction motor and a generator, which is mechanically coupled with the motor to provide different loads. Three induction motors with the same specifications but different health conditions are tested subsequently. The specifications of the motor are listed in Table 4.

To verify the efficiency of the proposed method under different operations. In the experiment, all the cases are tested under five representative loads $(0 \%, 20 \%, 40 \%, 60 \%$ and $80 \%)$ at $100 \%$ rated speed. All the operating conditions are summarized in Table 5. The eccentricity level of 
healthy case $<=0.07 \mathrm{~mm}$, of the eccentric motor are $0.5 \mathrm{~mm}$ and $1 \mathrm{~mm}$ respectively as shown in Fig. 12. Note that the motors are controlled under openloop mode, a no feedback mechanism that keeps a constant main supply frequency $50 \mathrm{~Hz}$ at $100 \%$ rated speed.

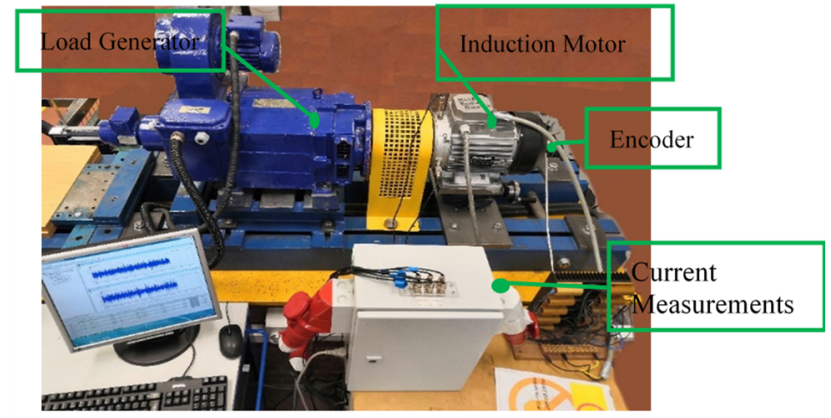

Fig. 11. The IM test rig

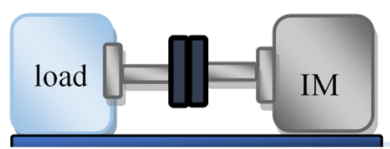

a) Baseline $(<=0.07 \mathrm{~mm})$

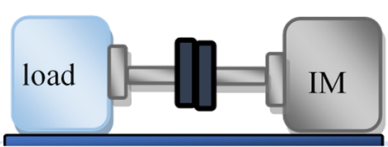

b) Misalignment $1(0.5 \mathrm{~mm})$

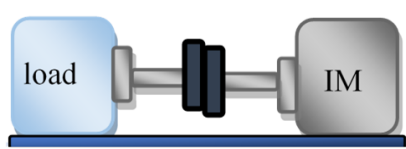

c) Misalignment $2(1 \mathrm{~mm})$

Fig. 12. Schematic diagram showing the degree of misalignment

Table 4. Specification of test motor

\begin{tabular}{|c|c|}
\hline Parameters & Value \\
\hline Rated voltage $(\Delta / Y)$ & $230 / 400 \mathrm{~V}$ \\
\hline Rated current $(\Delta / Y)$ & $15.9 / 9.2 \mathrm{~A}$ \\
\hline Motor power & $4 \mathrm{~kW}$ \\
\hline Number of phases & 3 \\
\hline Pole Pairs & $2 \mathrm{Pairs}$ \\
\hline Supply frequency & $50 \mathrm{~Hz}$ \\
\hline Rated speed & $1420 \mathrm{rpm}$ \\
\hline Number of rotor bars & 28 \\
\hline
\end{tabular}

Table 5. Test operations for EF test

\begin{tabular}{|c|c|c|c|c|c|c|}
\hline Degree of misalignment (mm) & \multicolumn{5}{|c|}{ Load (\%) } & Speed (\%) \\
\hline$<=0.07$ & 0 & 20 & 40 & 60 & 80 & 100 \\
\hline 0.50 & 0 & 20 & 40 & 60 & 80 & 100 \\
\hline 1.00 & 0 & 20 & 40 & 60 & 80 & 100 \\
\hline
\end{tabular}

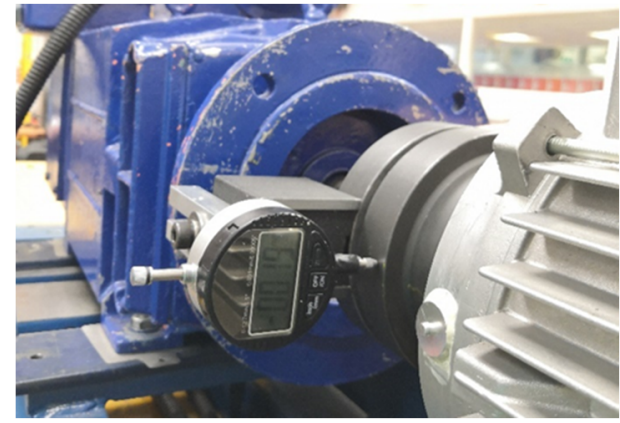

a) Eccentricity measurement

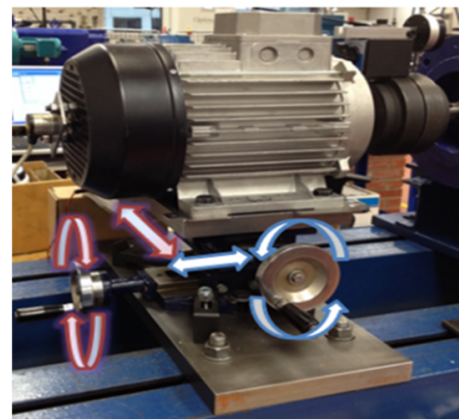

b) Introducing eccentricity

Fig. 13. a) Eccentricity measurement and, b) introducing the eccentricity into the induction motor 
The eccentricity fault was seeded into the test rig with different severities. As mentioned in Section 1, misalignment is the main cause of static EF. Therefore, misalignment is made in this research experimental study to make EF. The degree of eccentricity was measured using a dial indicator. The dial indicator was installed on its magnetic base, which can be attached to the coupling to guide the positioning of the motor, see Fig. 13(a). Fig. 13(b) illustrates changing the eccentricity by adjusting the two-axis compound table. The parameters of the instrument are listed in Table 6.

Table 6. Parameters of dial indicator

\begin{tabular}{|c|c|}
\hline Manufacturer & Matrix coventry gauge and tool \\
\hline Range & $0-12.7 \mathrm{~mm} / 0.5$ inch \\
\hline Resolution & $0.001 \mathrm{~mm} / 0.00005$ inch \\
\hline
\end{tabular}

\section{Data analysis and result discussion}

The supply frequency, $f_{s}$ in openloop control mode is constant at $50 \mathrm{~Hz}$. The rotational frequency, $f_{r}$, can be calculated using the encoder signal. According to Eq. (1), the eccentricity frequency, $f_{e f}$ equals the rotational frequency $f_{r}$. The fault information will be contained in the modulation of the supply signal $(50 \mathrm{~Hz})$. Take the lower sideband $\left(f_{s}-f_{e f}\right)$ frequencies of the two EF cases as the example. According to Eq. (2), the lower eccentricity-related sideband frequency equals the supply frequency minus the eccentricity frequency $\left(f_{\text {efsideband }}=f_{s} \pm f_{\text {ef }}\right)$ and they are listed in Table 7.

Table 7. Eccentricity frequency for healthy motor and EF cases

\begin{tabular}{|c|c|c|c|c|c|}
\hline \multirow{2}{*}{ Case } & \multicolumn{5}{|c|}{ Eccentricity frequency (Hz) } \\
\cline { 2 - 6 } & Load: $0 \%$ & $20 \%$ & $40 \%$ & $60 \%$ & $80 \%$ \\
\hline Healthy & 24.95 & 24.77 & 24.57 & 24.32 & 24.03 \\
\hline EF0.5mm & 24.95 & 24.77 & 24.55 & 24.30 & 24.02 \\
\hline EF1mm & 24.95 & 24.77 & 24.55 & 24.32 & 24.02 \\
\hline
\end{tabular}

Table 8. Frequency of lower sideband for healthy motor and EF cases

\begin{tabular}{|c|c|c|c|c|c|}
\hline \multirow{2}{*}{ Case } & \multicolumn{5}{|c|}{ Sideband frequency $(\mathrm{Hz})$} \\
\cline { 2 - 6 } & Load: $0 \%$ & $20 \%$ & $40 \%$ & $60 \%$ & $80 \%$ \\
\hline Healthy & 25.05 & 25.23 & 25.43 & 25.68 & 25.97 \\
\hline EF0.5mm & 25.05 & 25.23 & 25.45 & 25.70 & 25.98 \\
\hline EF1mm & 25.05 & 25.23 & 25.45 & 25.68 & 25.98 \\
\hline
\end{tabular}

The current spectrums of healthy motor (Healthyop, where the subscript OP stands for openloop control mode), motor with $0.5 \mathrm{~mm}$ eccentricity (EF0.5 $\mathrm{OP}$ ) and motor with $1 \mathrm{~mm}$ eccentricity $\left(\mathrm{EF} 1_{\mathrm{OP}}\right)$ is shown in Fig. 14. The supply frequency is stable at $50 \mathrm{~Hz}$ under all three conditions. According to the lower EF sidebands in Table 8, the sidebands around $25 \mathrm{~Hz}$ are related to an EF. Under $0 \%$ load (solid dark blue line in Fig 14), the amplitude of the sidebands increases as the eccentricity increases. However, the sidebands under other loads are not clear. To better observe the sideband amplitude, the lower sidebands under the three operating conditions in the range from $25 \mathrm{~Hz}$ to $26 \mathrm{~Hz}$ are shown in Fig 15.

Fig. 15 shows the frequencies of the EF sidebands increase as load increases. Unlike the BRB fault, the amplitude of the fault indicator for the EF decreases as the load increases. The fault indicators are clear to observe under light loads, but almost buried in the noise under heavy loads, especially $60 \%$ and $80 \%$ loads.

Using the Hilbert-based envelope method to extract the fault information, the derived spectrum in Fig. 16 confirms that envelope analysis can extract eccentricity information from the current signal. Similarly, with the spectrum analysis, the peak amplitudes at fault frequencies in the envelope spectrum decrease as the load increases and are nearly buried in the noise and 
interference under high loads, at and above $40 \%, 60 \%$ and $80 \%$, see Fig. 17(b). Compared with spectrum analysis (Fig. 17(a)) envelope analysis shows better performance in separating the EF1 $1_{\mathrm{OP}}$ case with the highest amplitudes at $0 \%$ to $60 \%$ loads but shows better capability when separating healthy and EF0.5OP under $20 \%, 60 \%$ and $80 \%$ loads.
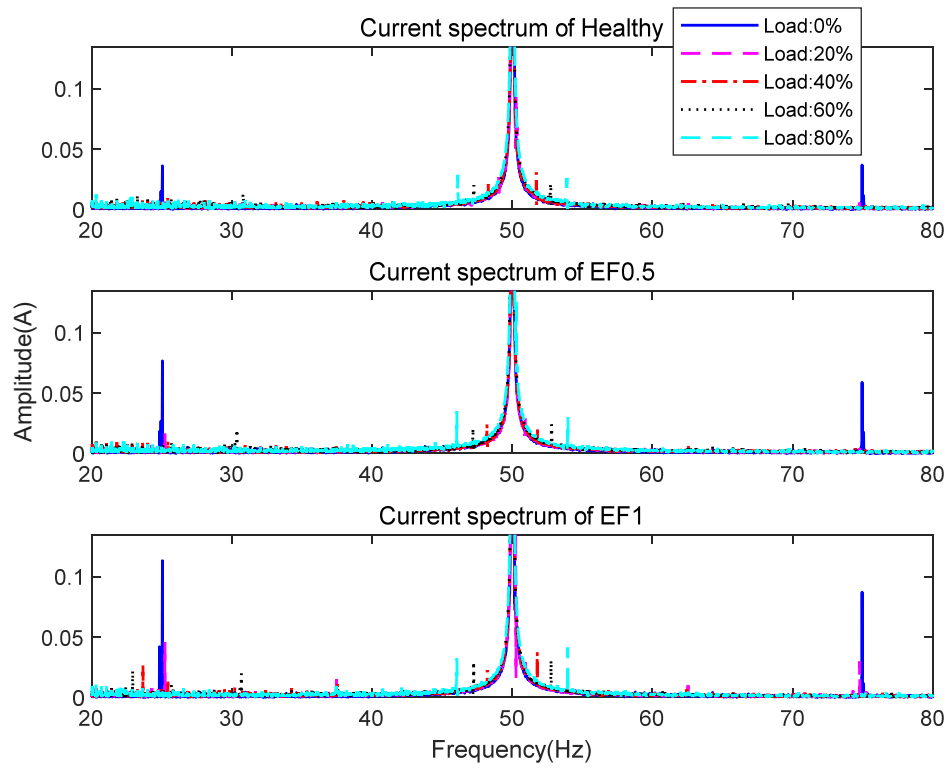

Fig. 14. Current spectrum of a) healthy motor, b) motor with $0.5 \mathrm{~mm} \mathrm{EF}$, c) motor with $1 \mathrm{~mm} \mathrm{EF}$ for various loads
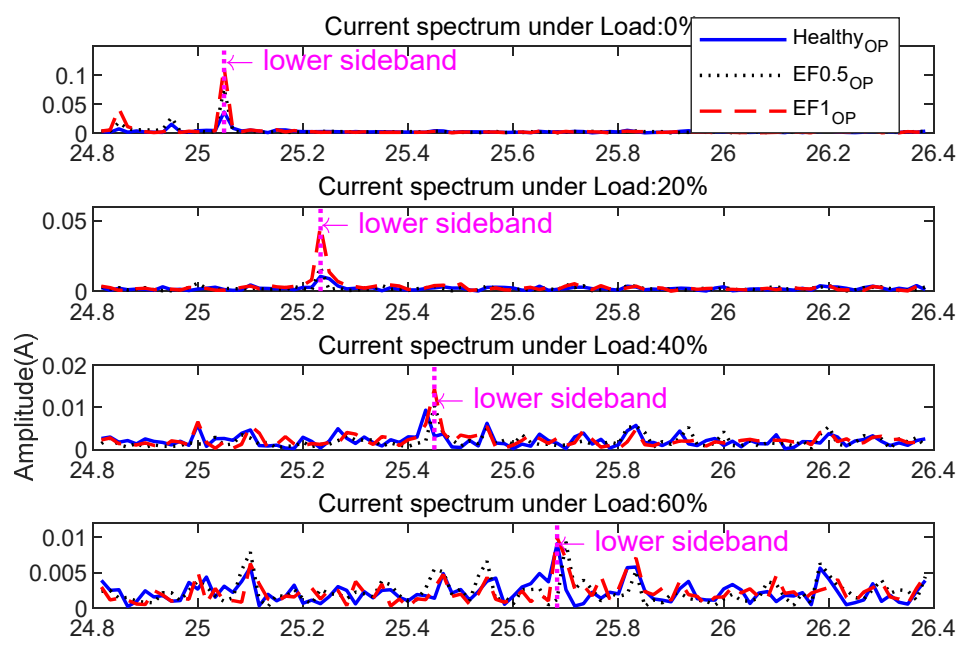

Current spectrum under Load:80\%

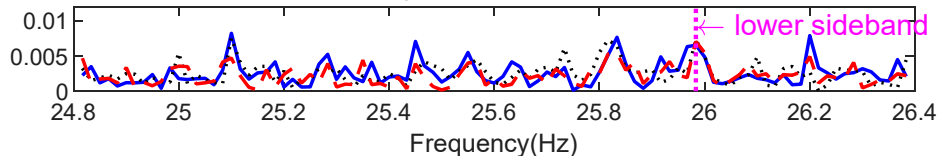

Fig. 15. Current spectrum showing lower sideband for healthy motor and motor with EF0.5OP, and motor with EF1OP under various loads

The amplitudes of the lower sidebands in the spectrum, see Fig. 17(a), increase as the degree of eccentricity increases under loads of $0 \%, 20 \%, 40 \%$, and $60 \%$. But it is difficult to separate 
the two eccentricity levels with a load of $80 \%$.

The analysis results under different loads show the fault indicator increase when the eccentricity increase which consistent with the proposed model analysis under different loads, especially under light loads, which verify the correctness of the model of eccentricity. The result under higher loads does perform as well as under light loads which illustrate the eccentricity motor is more difficult to diagnose under heavier loads.

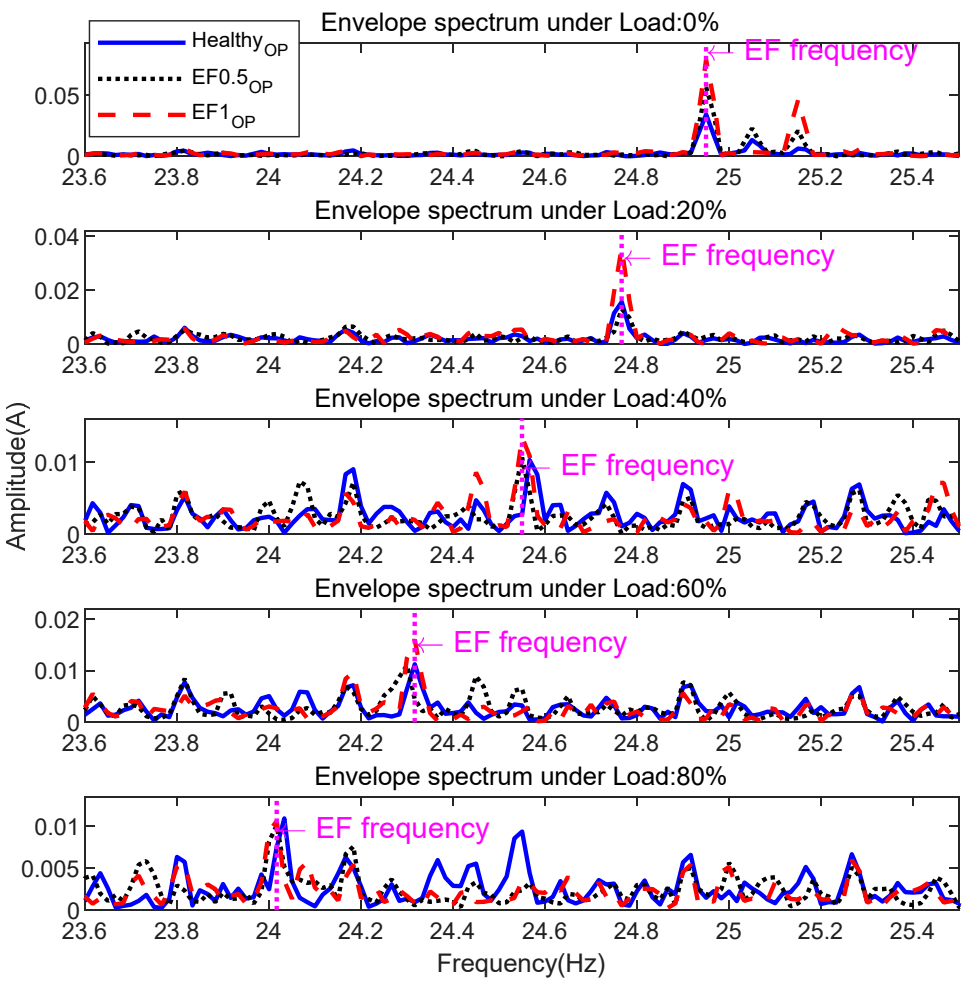

Fig. 16. Envelope spectrum for healthy motor and motor with EF0.5oP, and motor with EF1op under various loads
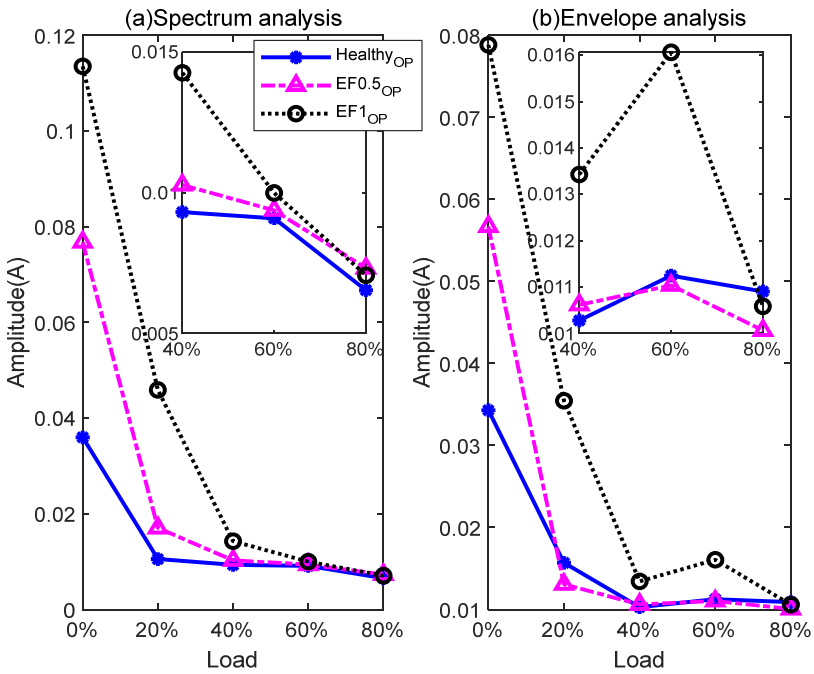

Fig. 17. Amplitudes of EF indicators under various loads using a) spectrum analysis b) envelope analysis 


\section{Conclusions}

This study develops AC motor models with eccentric effects. It firstly studies motor current spectrum behavior when there are different degrees of rotor eccentricity along. Subsequently, the behavior is also investigated when dynamic loads were applied to the eccentric motor, which is a typical situation due to residual dynamic unbalance and misalignment. The key findings of this study can be summarized as follows: the eccentricity fault leads to changes in air-gap flux as the rotor rotates. The inductance, including the stator self-inductance, rotor self-inductance and mutual inductance will change with the air gap. The simulated stator current spectrums for different degrees of eccentricity fault and dynamic load fault show that in the baseline case (healthy motor) no fluctuation occurred in the motor speed and no sidebands are observed. However, introducing an eccentricity fault causes fluctuation in the motor speed, which increases as the eccentricity fault increases. Eccentricity induces fault-related sidebands, which increases in amplitude as the eccentricity fault becomes more serious. For the balance (no eccentricity) motor, the sidebands of cases under the dynamic load are higher than under constant load. And the speed fluctuates more than the constant load cases. However, when the motor is with eccentricity, the sidebands of the dynamic load cases in the spectrum and the speed fluctuations related to the original angle. Among them, the amplitude at a rotating frequency which regarded as the fault indicator has been experimentally certificated increase when eccentricity getting serious.

\section{References}

[1] Y. Liu and A. M. Bazzi, "A review and comparison of fault detection and diagnosis methods for squirrel-cage induction motors: State of the art," ISA Transactions, Vol. 70, pp. 400-409, Sep. 2017, https://doi.org/10.1016/j.isatra.2017.06.001

[2] P. C. Sen, Principles of Electric Machines and Power Electronics. John Wiley \& Sons, 2007.

[3] S. Chapman, Electric Machinery Fundamentals. Tata McGraw-Hill Education, 2005.

[4] W. T. Thomson and A. Barbour, "On-line current monitoring and application of a finite element method to predict the level of static airgap eccentricity in three-phase induction motors," IEEE Transactions on Energy Conversion, Vol. 13, No. 4, pp. 347-357, 1998, https://doi.org/10.1109/60.736320

[5] D. Hyun, S. Lee, J. Hong, S. Bin Lee, and S. Nandi, "Detection of airgap eccentricity for induction motors using the single-phase rotation test," IEEE Transactions on Energy Conversion, Vol. 27, No. 3, pp. 689-696, Sep. 2012, https://doi.org/10.1109/tec.2012.2198218

[6] J. R. Cameron, W. T. Thomson, and A. B. Dow, "Vibration and current monitoring for detecting airgap eccentricity in large induction motors," IEE Proceedings B Electric Power Applications, Vol. 133, No. 3, p. 155, 1986, https://doi.org/10.1049/ip-b.1986.0022

[7] J. Hong, D. Hyun, S. B. Lee, and C. Kral, "Offline monitoring of airgap eccentricity for inverter-fed induction motors based on the differential inductance," IEEE Transactions on Industry Applications, Vol. 49, No. 6, pp. 2533-2542, Nov. 2013, https://doi.org/10.1109/tia.2013.2264793

[8] S. B. Chaudhury, M. Sengupta, and K. Mukherjee, "Experimental study of induction motor misalignment and its online detection through data fusion," IET Electric Power Applications, Vol. 7, No. 1, pp. 58-67, Jan. 2013, https://doi.org/10.1049/iet-epa.2012.0129

[9] A. Sapena-Bano et al., "Harmonic order tracking analysis: a novel method for fault diagnosis in induction machines," IEEE Transactions on Energy Conversion, Vol. 30, No. 3, pp. 833-841, Sep. 2015, https://doi.org/10.1109/tec.2015.2416973

[10] A. H. Bonnett and T. Albers, "Squirrel-cage rotor options for AC induction motors," IEEE Transactions on Industry Applications, Vol. 37, No. 4, pp. 1197-1209, 2001, https://doi.org/10.1109/28.936414

[11] R. Jigyasu, A. Sharma, L. Mathew, and S. Chatterji, "A review of condition monitoring and fault diagnosis methods for induction motor," in 2018 Second International Conference on Intelligent Computing and Control Systems (ICICCS), pp. 1713-1721, Jun. 2018, https://doi.org/10.1109/iccons.2018.8662833

[12] G. Dalpiaz and U. Meneghetti, "Monitoring fatigue cracks in gears," NDT and E International, Vol. 24, No. 6, pp. 303-306, Dec. 1991, https://doi.org/10.1016/0963-8695(91)90003-1 
[13] M. E. H. Benbouzid, "A review of induction motors signature analysis as a medium for faults detection," in IECON '98. 24th Annual Conference of the IEEE Industrial Electronics Society, Vol. 47, No. 5, pp. 984-993, 2000, https://doi.org/10.1109/iecon.1998.724016

[14] R. R. Schoen and T. G. Habetler, "Effects of time-varying loads on rotor fault detection in induction machines," IEEE Transactions on Industry Applications, Vol. 31, No. 4, pp. 900-906, 1995, https://doi.org/10.1109/28.395302

[15] O. S. Olaleye, C. O. Ahiakwo, D. C. Idoniboyeobu, and S. Orike, "Modeling of eccentricity and performance of three-phase induction motors," Journal of Newviews in Engineering and Technology (JNET), Vol. 2, No. 1, 2020.

[16] E. S. Obe and A. Binder, "Direct-phase-variable model of a synchronous reluctance motor including all slot and winding harmonics," Energy Conversion and Management, Vol. 52, No. 1, pp. 284-291, Jan. 2011, https://doi.org/10.1016/j.enconman.2010.06.069

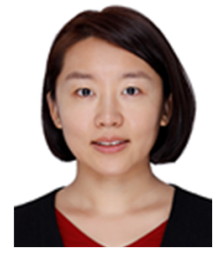

Haiyang Li got M.S. degree in School of Mechanical Engineering from Hebei University of Technology in 2014. Now she is a fulltime Ph.D. student at the University of Huddersfield and be sponsored by China Scholarship Council. She focuses on fault diagnosis and condition monitoring for induction motors based on instantaneous electrical signatures. Contribution: original draft preparation; review and editing. formal analysis; methodology.

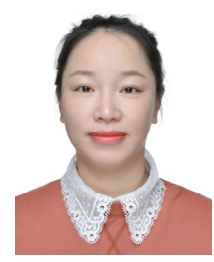

Zhexiang Zou is born in 1983 in Zhejiang Province, China. She currently an associate professor at School of Industrial Automation, Beijing Institute of Technology. The main research subjects are machine tool machining condition monitoring and diagnosis, current signal analysis and processing. Contribution: data collection; proofreading.

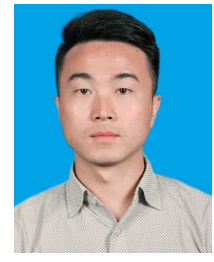

Xiuquan Sun is a Ph.D. candidate at the University of Huddersfield, UK who is currently working on the condition monitoring, tribology behavior and dynamic modelling of mechanical machineries such as gear transmission system, induction motor, IC engine etc. Contribution: programming; supporting algorithms.

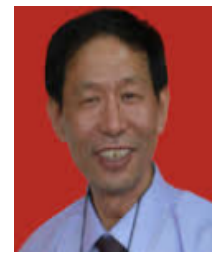

Fengshou Gu received the Ph.D. degree from the University of Manchester, Manchester, U.K., in 2008. He is currently a Professor at the University of Huddersfield, Huddersfield, U.K. He is one of the experts in the fields of machinery diagnosis and vibroacoustic analysis, with over 30 years of research experience. His research interests include system modelling, various physical parameter measurements, advanced signal processing, and fault diagnosis. Contribution: programming; project administration; conceptualisation; supervision.

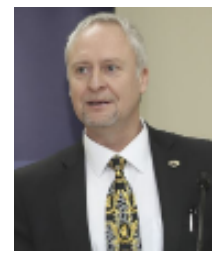

Andrew D. Ball obtained B.Eng. degree in mechanical engineering from University of Leeds in 1987. Then he received the Ph.D. in machinery condition monitoring from the University of Manchester, UK in 1991. He is currently a Professor and Pro-ViceChancellor at the University of Huddersfield (UoH). Also, he is the Director of the Centre of Efficiency and Performance Engineering (CEPE) at UoH. His research expertise is in the detection and diagnosis of faults in mechanical, electrical and electro-hydraulic machines, and in data analysis and signal processing. Contribution: resources. 